\title{
Concerning the possibilities of successional changes revealing in anthropogenically transformed ecosystems on the base of remote sensing and ground-based survey data integration
}

\author{
L.M. Kavelenova $^{1}$, N.V. Prokhorova ${ }^{1}$, E.S. Korchikov ${ }^{1}$, A.Yu. Denisova ${ }^{1}$, D.A. Terentyeva ${ }^{1}$ \\ ${ }^{1}$ Samara National Research University, 34 Moskovskoe Shosse, 443086, Samara, Russia
}

\begin{abstract}
The districts of Samara region are characterized by specific combination of orographic structure, hydrological regimes, soil and vegetation cover features, combined with a high level of anthropogenic pressure. The revealing of negative changes associated with the anthropogenic exploitation regimes incliding salinization and waterlogging after irrigation, soil erosion, transformation of non-cultivated fields into deposits, overgrowing of old quarries etc. seems to be a difficult task when carrying out by ground-based studies related to a large-scale land resources of the region. The use of remote sensing data, resulted by a time series of images for the same territory, opens up wide opportunities, on condition that the regional ground-based standardization is carried out.
\end{abstract}

Keywords: anthropogenic exploitation of ecosystems; overgrowing of non-cultivated fields and quarries; ground-based ecosystem survey; remote sensing data

\section{Introduction}

The Samara region is characterized by a complex combination of of orographic, hydrological, soil and vegetation features, in combination with a high level of anthropogenic pressure. The share of agricultural land in the region approaches to the level of $77 \%$ whereas for some administrative regions it exceeds 90\% (Alekseevsky, Bolshechernigovskiy, Bolsheglushitsky, Krasnoarmeisky, Pestravsky districts, where the share of tillage lands is more than 70\%) and has the minimum levels in Syzransky, Shigonsky, Stavropolsky administrative regions where more than $40 \ldots 50 \%$ belong to agricultural lands [1]. The result of plowing was the loss of most of the steppe lands, their plots could be preserved in point unusable for plowing (steppe yards, steep slopes of hills) [2,3]., These components of the landscape often are characterized by a high degree of erosion hazard. The territory of the region demonstrates is a tendency of the water logging processes intensification, especially for lands located in the zone of influence of the Kuibyshevskoye and Saratovskoye reservoirs and such large irrigation systems as Kutuluk, Vetlyanskaya, Spasskaya.

The total area of waterlogged agricultural lands is 127.1 thousand hectares or $3.3 \%$, of which not in river valleys are 70.5 thousand hectares, including 53.4 thousand hectares of arable land, where water logging is mainly due to anthropogenic impact [4]. Wetlands, mainly forage lands, occupy 25.7 thousand hectares or $0.7 \%$, of which $0.4 \%$ are bogged up in an average degree.

In recent decades, the formation of deposits (not cultivated for a long period of arable land plots) has been observed in the region. On the non-cultivated fields (deposits) the successive changes in the vegetation cover take place including stages as: in the first 2-3 years of idleness, the arable grows with annual and biennial plants, in the next 5-7 years rhizome plants dominate it, further vegetation develops characteristic of the steppe conditions. Further unused arable land in the forest-steppe zone overgrows with bushes and trees. The abandoned land is the source of the spread of weeds to active arable land [5]. The area of lands overgrown by shrubs and trees on formerly agricultural land in 2015 in the Samara region was 18.7 thousand hectares. The total area of agricultural lands with saline soils is 110.1 thousand hectares or $2.9 \%$, including arable land - 57.1 thousand hectares or $1.9 \%$. According to the degree of salinity in the soil profile, slightly saline soils predominate with easily soluble salts exceeding the toxicity thresholds. As a result of the irrigation regime disturbance, for example, drainage lack in conditions of close saline groundwater bedding, 11.2 thousand hectares of secondary saline arable land were identified [4, 6]. Agricultural lands with solonetsous soils and solonetzes were found on an area of 156.1 thousand hectares, including arable land - 65.0 thousand hectares (or $4 / 1$ and $2.2 \%$ respectively).

The identification of negative changes related to anthropogenic exploitation (soil erosion, salinization and waterlogging as a result of irrigation) and its cessation (conversion of non-cultivated fields into deposits, overgrowing of decommissioned quarries) presents a difficult task in carrying out ground-based research related to a large-scale land resources. The integrated terrestrial ecosystem surveys fulfillment, providing primary data for the subsequent remote sensing materials processing. Such materials seems to be presented by a temporary series of the same territory images, what opens up wide possibilities for monitoring the territory in aims of wide range of applied problems solving.

The specialized satellite imagery of resource assignment (Terra, Aqua, Landsat, etc.) makes it possible to receive information for a certain time period and with a certain spatial resolution. For retrospective monitoring elaboration, it is necessary to select and catalog satellite data, as well as to fulfill their processing, with the formation of spectral indices reflecting the state of different natural environment components. The methods of estimating recreational resources adjusted in this way allow to study and indicate the most threatened territories where intensification of unfavorable natural processes occurs, also as landscapes undergoing destruction, areas of phyto- and biodiversity reduction, as well as areas of increased man-caused and anthropogenic load [7]. As for our country, the practice of use time series images in the analysis of changes already finds its application in the 
Image Processing, Geoinformation Technology and Information Security / L.M. Kavelenova, N.V. Prokhorova et al.

monitoring of saline lands, technogenically violated forests, wetlands [8-10]. The experience of such researches abroad is also quite rich (see, for example, [11-15]).

As applied to the tasks set by us, three objects of anthropogenically transformed ecosystems were proposed as control polygons for the detection of various stages of negative changes in time. For them, we had information on their state about 30 ... 40 years ago). Specificity of selected polygons allowed us to assess among the negative changes in the dynamics: 1) the formation of pseudo-forest formations with different species composition on the deposited fields; 2) development of salinizated plots (solonetzes and solonchaks) under the influence of a closely located system of ponds (reservoirs); 3) the visualization of overgrowth stages on the bottom of the spent limestone quarry, which can be considered as model of the natural revitalization of the plant cover fully destructed by the open method extraction of mineral raw materials.

\section{Methods}

Three polygons were chose as models for the detection of various stages of negative changes in time, in which 2 - 5 reference plots were allocated (the total number of reference areas was 11):

1. "Neighborhoods of the Nizhnenikolsky village" (rural settlement Domashka, Kinel municipal district of the Samara region). The reference plots studied in 2016 are located $1.5 \mathrm{~km}$ to the north-north-west (reference plot 1 ) $2 \mathrm{~km}$ to the southsouth-west (reference plots 2-5) from the village of Nizhnenikolsky.

2. "Neighborhoods of the Pekilyansky Reservoir" (in the valley of the Gusikha river, $3 \mathrm{~km}$ to the south-west from the village of Pekilyanka, Bolshekhernigovsky district, Samara region). Within the boundaries of the polygon, the solonets meadow and solonchak with yields of salt crystals on the soil surface were studied (reference plots 6, 7).

3. The Ust-Soksky (Soksky, or Western) quarry is located on the northern macroslope of the western part of the Sokoliye Mountains, a few kilometers from the confluence of the river Sock in the Volga river (Saratov reservoir), in the Krasnoglinsky district of the Samara city (reference plots 8-11).

For these objects, we had information relating to a retrospective assessment of their state (in particular, for Nizhnenikolsky and Ust-Soksky quarry - 30 ... 40 years ago).

During the ground-based complex survey, the coordinates of the central points were determined using the GPS-binding using the GarminEtrex navigator, the soil and vegetation cover survey including projective covering of plants, the primary plant species lists were compiled. The data obtained were used to prepare brief ecological characteristics of the reference plots.

The following images were used to identify the objects in polygon areas:

1) "Geoton", spacecraft Resource-P, spatial resolution $0.8 \mathrm{~m}$. To create a georeferenced image, panchromatic and multispectral images were used. The panchromatic image (black and white) has a resolution of 0.8 meters, the multispectral image is 2.4 meters and contains four channels: red, green, blue and infrared. To create a color image with a resolution of 0.8 meters, a panchromatic image was used to enhance the spatial resolution of the multispectral image, after processing which resulted in a complex image. The image was then re-calculated from the standard WGS-84 coordinate system into the local system of the Samara region and superimposed on the region map. The image was tied with a precision of 2 pixels, that is, up to 1.6 meters. For binding, a second-order polynomial transformation with support points and an accurate relief model was used.

2) Spot-7, spacecraft SPOT-7, spatial resolution of $1.5 \mathrm{~m}$. To create a multispectral image with a resolution of $1.5 \mathrm{meters,}$ software was used to process data from SPOT6 / 7 satellites. The image was then re-calculated from the standard WGS-84 coordinate system into the local system of the Samara region and superimposed on the region map. The image was attracted to within 2 pixels, that is up to 3 meters. For binding, a second-order polynomial transformation with support points and an accurate relief model was used.

3) GoogleEarth. GoogleEarth data are freely available on the Internet. These images have a high resolution, but inaccurate binding (sometimes error of up to 50 meters). Before processing the image data, they were saved in the tiff format, then manually bound using the Raster Manager in the InGeo GIS. It was used to bind the projective transformation using five or more control points.

Using the method of regression tree [16], classifiers were constructed for each polygons, which make it possible to extract territories with similar characteristics of soil cover in space images. As attributes for the classifier, brightness, red, green, blue, and near infrared spectral channels were used; the normalized difference The vegetative index (NDVI) based on NIR and G channels [17], the chlorophyll coefficient [18], the local average in the $3 \times 3$ window, variance, correlation coefficients and entropy, textural signs of Haralick [19] and Gabor [20]. The resulting set of 41 traits using the principal component transformation led to reduced representation with a smaller number of features used for classification.

The experiments included the training of the classifier and its verification on remote sensing images with different spatial resolution. Since the data in the infrared channel was available only for images of Spot-7 and Geoton spacecraft, it was for these photographs that experimental studies were carried out. The spatial resolution of the images was $1.6 \mathrm{~m}$ and $0.8 \mathrm{~m}$, respectively. The purpose of the experiments was to determine the best number of main components $\mathrm{N}$ to construct a classifier. The evaluation of the classification error was performed by cross-validation for 100 launches of training and classification procedures. In all experiments, a lot of data with known results of ground surveys were divided into training and control samples in the ratio $75: 25$ respectively. 


\section{Results and Discussion}

The results of ground surveys allowed us to characterize the state of the parts of the polygon reference plots taking into account the specificity of the succession changes connected with the changes in anthropogenic exploitation state in past years.

Polygon "Neighborhoods of Nizhnenikolsky", located in the valley of the Samara river, demonstrates a leveled mesorelief with an absolute height of $45 \ldots 47 \mathrm{~m}$ above sea level. In general, the vicinity of Nizhnenikolsky village is confined to the valley of the Samara river (left bank), from the floodplain to the floodplain terraces and watershed. Steppe, meadow-steppe and ruderal-steppe plant communities, also as pseudo-forest plant communities at different succession stages, monocenoses of agricultural crops (in 2016 - sunflower fields, winter cereal crops, etc.) are represented here. The relief is mostly heterogeneous, with frequent depressions rounding lakes, altered with plane elevations. Until the 1990s, plains were almost completely used for agriculture, forests with the participation of various willows and poplars and an admixture of other tree species $f$ filled the depressions along the channels of temporary watercourses and formed along the lakes shores. Later, the plowing of some of the lands ceased, and the development of deposits began on them, in recent years some fallow lands have been reintroduced into agricultural land. The reference plots laid in 2016 are represented by fallow areas (cessation of agricultural cultivation for more than 20 years), which are in the process of development of the steppe (reference plot 4), semi-shrub (reference section 3) and pseudo-forest communities (reference plots 1,2 And 5).

Reference plot 1 is a non-cultivated field on which a steppe community (mixed-grass-grass associations) was formed with Ulmus pumila L. (karagach), undergrowth of trees and shrubs. The occurrence of such communities with the participation of the $U$. pumila is observed in the steppe regions of the Samara region on elevated leveled relief forms in the absence of excessive moisture. The tree component of the non-cultivated field is characterized by a height of up to $8 \mathrm{~m}$, a crown density up to 0.2 $(20 \%)$. The share of the open soil surface was less than $1 \%$. The site shows fresh porpoises of wild boars. The reference plot 2 is a non-cultivated field transformed to a pseudo-forest community formed by Elaeagnus angustifolia L., aged over 15 years, with a height of 6-8 m, crown diameter from 3 to $5 \mathrm{~m}$, an average crown density up $0.5(50 \%)$. The grass cover is formed by herbagegrass association. The open surface of the soil is not expressed. Harvesting of farmland by E. angustifolia is typical for the southern parts of the region in relief depressions with partial soil salinization. Reference plot 3 is a non-cultivated field, now transformed to a steppe community in the form of a wormwood-grass association with wormwood dominating. The height of the grass reaches $1 \mathrm{~m}$ with a projective covering is more than $80 \%$. The open surface of the soil is not expressed. In the places where the cattle are run, the ruderal nature of plant cover is presented clearly. Reference plot 4 is a non-cultivated field, now turned into a steppe herbage-grass association with dominance of grasses. The height of the grass is on the average $30 \mathrm{~cm}$, the projective covering is more than $80 \%$. The open surface of the soil is not expressed. Reference plot 5 is a non-cultivated field, now is a steppe community in the form of a herbage-grass association on the initial stage of E. angustifolia overgrowth. The projective coverage of the grass stand is more than $80 \%$. Young E. angustifolia trees have a height of up to $1.5 \mathrm{~m}$ with a crown density sometimes up to $0.6(60 \%)$, and an average of $0.35(35 \%)$. The open surface of the soil is also not expressed.

Experiments on the classification of the Nizhnenikolsky areas showed that the lowest classification error is achieved with the use of the 9 main components of the system of characteristics under consideration, while the probability of correct classification for images of the Spot-7 was 78\% and 74\% for the "Geoton" data. The reduction of detection efficiency in comparison with a more coarse resolution image should be attributed to the use of small spatial windows to calculate texture attributes $(3 \times 3$ pixels windows were used in the experiment). As a result, in a higher resolution image, a larger number of points were required for a single surface object of the same size, so larger windows should be used to characterize the intensity of brightness changes within a certain window. However, increasing the window size with a larger image size will significantly increase the processing time, therefore it is recommended to use the images of the Spot-7 with a resolution of $1.6 \mathrm{~m}$. The study shows that the best imade identification was achieved for pseudo-forest communities. Steppe communities were classified the worst. Pseudo-forest communities according to subspecies (dominated by Ulmis pumila or Elaeagnus angustifola) can not be classified relative to each other.

Table 1. Formalized results of classifier training and its verification on remote sensing images of reference plots.

\begin{tabular}{|c|c|c|}
\hline \multirow{2}{*}{ Criteria } & \multicolumn{2}{|c|}{ The results of image processing } \\
\hline & SC Spot-7 & SC "Geoton" \\
\hline \multicolumn{3}{|c|}{ "Nizhnenikolsky" } \\
\hline Optimum number of main components $\mathrm{N}$ & 9 & 9 \\
\hline Probability of correct detection & $78 \%$ & $74 \%$ \\
\hline \multicolumn{3}{|c|}{ "Neighborhoods of the Pekilyansky Reservoir" } \\
\hline Optimum number of main components $\mathrm{N}$ & $\begin{array}{c}3 \\
\text { (from } 3 \text { to 12) }\end{array}$ & 9 \\
\hline Probability of correct detection & $99 \%$ & $98 \%$ \\
\hline \multicolumn{3}{|c|}{ Ust-Soksky quarry } \\
\hline Optimum number of main components $\mathrm{N}$ & 9 & 9 (from 6 to 9 ) \\
\hline Probability of correct detection & $92 \%$ & $85 \%$ \\
\hline
\end{tabular}

The classifier constructed for the plots 2-5 of the polygon "Nizhnenikolsky" was used for the plot 1 . The classification results $(\mathrm{N}=9)$ showed that the site number 1 is classified in the same group as the site number 2 , that is, refers to the pseudo-forest 
Image Processing, Geoinformation Technology and Information Security / L.M. Kavelenova, N.V. Prokhorova et al.

community. However, as was mentioned above, it was not possible to establish differences in the species composition of the tree layer of these pseudo-forest communities (overgrowing with Ulmis pumila or Elaeagnus angustifola) during the analysis of the plot images.

The polygon "Neighborhoods of the Pekilyansky Reservoir" is confined to the southern part of the Samara Region, which is characterized by a high degree of plowing of the indigenous steppes. The reduction of the cultivated lands area in the late 1990s led to the formation of non-cultivated fields with various forms of ruderalized, steppe and meadow plant communities. Cattle grazing, in some places haymaking are carried out.

The formation of ponds and reservoirs in the damming of watercourses (for the considered landfill, the Gusikha River), which are used for water supply, irrigation and fish farming, is a characteristic feature of territory. The secondary salinization of the soil cover occurs in the adjacent areas of these ponds. The Gusikha river valley possessing solonets soils complex is used for hayfields and pastures. Reference plot 6 is located to the north-east of Pekilyansky reservoir, the creation of which resulted in soil cover secondary salinization. The vegetation is represented by a solonetz meadow, in the herbaceous cover with domination of Artemisia pauciflora Web. and Atriplex verrucifera Bieb. The average projective coverage of the grass is $85 \%$, the open soil surface is about $5 \%$. The degree of salinity can be characterized as moderate, what is confirmed by the nature of the formed ecosystems. The reference plot 7 is also located to the north-east of the Pekilyansky reservoir. Its soil cover is characterized by a pronounced secondary salinity, that was clearly indicated by changing the color of the grass stand, manifested from the middle of the vegetative period. The soil is represented by a solonchak, with typical halophytes vegetation, where Suaeda corniculata (C.A. Mey.) Bunge and Salicornia europaea L. dominate. The average projective coverage of the grass is $45 \%$, and areas with open surface soil - 55\%. On the surface of the open soil there is a whitish-yellowish crust of salt deposits, extending from the surface to a depth of $5 \mathrm{~mm}$.

When working with Spot-7 images of the polygon "Neighborhoods of the Pekilyansky Reservoir", the previously described procedure was fulfilled and showed that 3 to 12 main components of the characteristics system can be used to classify the etalon areas, the classifier provides a correct classification probability of about $99 \%$ (See table 1). It should be noted that it is reasonable to select as few signs as possible to accelerate the calculations, therefore the optimal choice in this case can be considered 3 main components. The training and classification results for "Neighborhoods of the Pekilyansky Reservoir" according to the data of the "Geoton" showed that the application of 9 main components led the best result, with the classifier providing the correct detection probability of the level of $98 \%$. The images combination showed that the classifier error should be attributed to the displacement of the mask relative to the snapshot, which indicates the need for a very accurate snapping for the images that the classifier is trained on. The study showed that strong soil salinity points with $55 \%$ bare soil surface (plot 7 of the polygon "Neighborhood of the Pekilyansky Reservoir"), is well diagnosed from images.

Ust-Soksky (Soksky, or Western) quarry is located on the northern macro-slope of the western part of the Sokoliye Mountains, a few kilometers from the confluence of the river. Sok in the Saratov Reservoir in the Krasnoglinsky district of Samara city. It represents the oldest site of the Soksky carbonate deposit, where industrial extraction of carbonate rocks was carried out for the production of building materials (crushed stone, quarry stone, construction mixtures). As a result on the northern slope of the Sokol'y Mountains, a large trough-shaped technogenic excavation arose having maximum length along the bottom from north to south about $1 \mathrm{~km}$ and from west to east more than $2 \mathrm{~km}$. The relative height of the steep sides of the manmade trench reaches tens of meters, in some cases - 100-150 m. Many times after the operation of the quarry the new dumps of household and construction debris (no more than $5 \%$ of the floor area) were created. This time, the sub-eastern side of the quarry is storing off-grade rock from the Central and Eastern sections of the Soksky deposit, which does not affect the bottom of the quarry, but is distributed only along its terraces. The recent years trend has been the use of the central and western parts of the bottom under the shooting range, as well as the organization of walking tours and quadrocycles to the local lake and entrances to the tunnel. Since the early 70's. XX century the industrial extraction of building materials in the Ust-Soksky quarry was stopped and the processes of natural self-growth and primary soil formation began to develop. The reference plot 8 (in the eastern part of the Ust-Soksky quarry) presents the forest amphicycenosis formed during 40 years overgrowth of trees of Populus nigra L., Betula pendula Roth. and Pinus sylvestris L. (1: 1: 1) on bottom of the quarry. The grass cover under the canopy of tree vegetation and on open positions practically is not expressed. The height of the tree layer is up to 8-10 m, the crown density is $0.6(60 \%)$, the share of the open rocky surface (dolomites, limestones) is $0.4(40 \%)$. Reference plot 9 (in the central part of the quarry near the lake) cam be described as forest amphicycenosis, formed in the process of 40-year overgrowing by Populus nigra L. and Salix caprea L. in the ratio of 9: 1. The grass cover is almost indistinguishable, but on the stony substrate there are separate clumps of green moss. The height of the tree storey is 6-9 m, the crown density is 0.8 ( $80 \%$ ), the share of the open rocky surface (dolomite, limestone) is $0.1(10 \%)$. Reference plot 10 (in the central part of the quarry opposite the galleries) presents forest amphitocenosis formed in the process of 35 years overgrowing by Populus nigra L., Pinus sylvestris L. and Betula pendula Roth. in a ratio of 6: 2: 1 with an admixture of Populus tremula L. and various willow species. The grass cover is almost not expressed. The height of the tree layer is $3-5 \mathrm{~m}$, the crown density is $0.3(30 \%)$, the share of the open stony surface (dolomites, limestones) is $0.7(70 \%)$. The reference plot 11 (in the western part of the quarry) was formed during 35 years of overgrowing as forest amphitocenosis with a stand represented by a Populus nigra L., Pinus sylvestris L. and Betula pendula Roth. in a ratio of 4: 4: 2 . The grass cover is almost not expressed. The height of the tree layer is $1.5-3 \mathrm{~m}$, the crown density is $0.2(20 \%)$, the share of the open rocky surface (dolomites, limestones) is $0.8(80 \%)$.

For the polygon Ust-Soksky quarry plots, according to the previously described methodology, it was obtained that 9 or more major components of the feature system provide a high quality of classification, while the probability of correct classification is approximately 92\% (see Table 1 ). The results of training and classification of instrumentation and instrumentation "Ust-Soksky quarry" according to the GA "Geoton" allowed to conclude that here for the identification of plant communities can be used 
Image Processing, Geoinformation Technology and Information Security / L.M. Kavelenova, N.V. Prokhorova et al.

from 6 to 9 main components of the characteristics system. The study showed that the parts of the Ust-Sok quarry can be classified using remote sensing data, while a smaller classification error is ensured by using images of the Spot-7 spacecraft with 9 main components in the system of signs.

\section{Conclusion}

Thus, the results of complex field surveys on three test sites (polygons) in different parts of Samara region, integrated with the selection of RS data Spot-7, Geoton, GoogleEarth for this territory, were used for the development of in the assessing territorial resources methodology with geodata classifiers. The use of regression tree method based on textural features number showed the undoubted promise of this approach in identifying of regionally significant negative symptoms of land cover state. With the smallest error in sucession changes revealing in anthropogenically transformed ecosystems, it is advisable to use images of the SPOT-7 spacecraft with a spatial resolution of $1.5 \mathrm{~m}$. It is important to develop this methodology for achieving in future a more detailed classification of regional vegetation types in photographs, in particular - different types of forest communities.

\section{Acknowledgements}

The authors are grateful to the Autonomous State Institution of the Samara Region "Center for Innovative Development and Cluster Initiatives" for the opportunity to carry out this study.

\section{References}

[1] Poroshina LN. The Atlas of the Lands of the Samara Region. Samara, 2002; 101 p. (in Russian)

[2] Kavelenova LM, Rozno SA, Pomogaybin AV, Ruzaeva IV, Zhavkina TM, Soboleva MN, Pomogaibin EA, Demenina LG. Some aspects of the preservation of phytodiversity in anthropogenically transformed environment (by the example of the Samara region). Izvestiya of the Samara Scientific Center of the Russian Academy of Sciences 2012; 14: 1(9): 2233-2236. (in Russian)

[3] Kavelenova LM, Prokhorova NV, Golovlyov AA, Rozno SA. Preservation of phytodiversity as an integral part of sustainable development strategy in the Samara region. Volga Ecological Journal 2014; 1: 12-20. (in Russian)

[4] State report on the state of the environment and natural resources of the Samara region for 2014. Samara, 2015; 25: 298 p. (in Russian).

[5] Ledovskikh AA, Kalashnikova EB. The problem of "abandoned" lands in the Samara region. Approbation 2015; 6(33): 107-109. (in Russian)

[6] State report on the state of the environment and natural resources of the Samara Region for 2015. Samara, 2016; 26: 296 p. (in Russian)

[7] Shevyrev SL, Antsiferova GA, Shevyrev MZh. On the satellite monitoring of mining enterprises of Primorsky Krai (on the example of the Pavlovsky-2 section). Bulletin of the VSU. Ser. Geology 2015;2: 128-133. (in Russian)

[8] Lyamina VA, Glushkova NV, Smolentseva EN, Zolnikov ID. Use of GIS and ERS methods for monitoring the area of lakes and solonchaks in the south of Western Siberia. Interexpo Geoiberia 2010; 2: 3-7. (in Russian)

[9] Cherosov MM, Ammosova EV, Savvin TI, Vinokurov EN, Tarasov IM. Experience in the use of GIS technologies and remote sensing for assessing the impact of anthropogenic factor on the vegetation of individual territories of Yakutia. Advances in modern natural science 2012; 11(1): 63-65. (in Russian)

[10] Glushkova NV, Chupina DA, Kotler S.A. Analysis of the dynamics of saline complexes for assessing the degree of aridization of the territory of western Siberia on the basis of GIS and DZ. Interexpo Geo-Siberia 2013: 2: 77-81. (in Russian)

[11] El-Asmar HM, Hereher ME. Change detection of the coastal zone east of the Nile Delta using remote sensing. Environ. Earth Sci. $2011 ; 62$ (4): 769-777.

[12]Rebelo LM, Finlayson CM, Nagabhatla N. Remote sensing and GIS for wetland inventory, mapping and change analysis. J. Environ. Manage 2009; 90: $2144-2153$.

[13]AlaviPanah SK. Goossens R. Relationship between the Landsat TM, MSS data and soil salinity. J. Agric. Sci. Technol. 2001 ; 3: $21-31$.

[14]Eldeiry AA, Garcia LA. Detecting soil salinity in alfalfa fields using spatial modeling and remote sensing. Soil Sci. Soc. Am. J. $2008 ; 72(1)$ : 201-211.

[15]Kalra NK, Joshi DC Potentiality of Landsat, SPOT and IRS satellite imagery, for recognition of salt affected soils in Indian Arid Zone. J. mote Sens 1996; 17(15): 3001-3014.

[16] Kuznetsov AV, Myasnikov VV. Comparison of algorithms for controlled element-wise classification of hyperspectral images. 10; 494-502. (in Russian)

[17] Pettorelli N, Mysterud AGaillard J-M. Tucker CJ, Stenseth NC. Using the satellite-derived NDVI to assess ecological responses to environmental. Trends in ecology \& evolution. 20; 9: 503-510.

[18] Marx A. Erkennung von borkenkäferbefall in fichtenreinbeständenmit multi-temporalenrapideye-satellitenbildern und datamining-techniken. Mysterud, JPhotogrammetrie, Fernerkundung, Geoinformation 4: 243-252.

[19] Haralick RM. Textural features for image classification. Environ. Manage 2009 RJ; 90. J. Environ. Manage 2009; 90. IEEE Transactions on systems, man, and cybernetics, $1973 ; 6: 610-621$.

[20] Fogel I. Gabor filters as texture discriminator. Biological cybernetics 1989; 61(2): 103-113. 